\title{
DA VIDA APRISIONADA ÀS ESCRITAS INSURGENTES
}

\author{
Rafael Caetano do Nascimento ${ }^{1}$
}

\section{Adentrar, escutar, grafar: cartografia na prisão}

Adentrar a prisão. Perseguir os rastros de uma prática solitária, e povoada. Silenciosos gritos. Cultivar uma atenção às linhas de força que dizem algo ou que deixam algo a dizer. Linhas ligeiras que passam sempre por todos os lados. Encontrá-las para ser encontrado: ir ao encontro. Captar e ser capturado. Cartografia do escrever em privação de liberdade.

Pesquisar talvez seja mesmo ir por dentro da chuva, pelo meio de um oceano, sem guarda-chuva, sem barco. Logo, percebemos que não há como indicar caminhos muito seguros ou estáveis. Pesquisar é experimentar, arriscar-se, deixar-se perder. [...]. A vontade de aportar com segurança faz corrermos o risco de restrição do potencial da viagem. (OLIVEIRA \& PARAÍSO, 2012, p. 161).

Pesquisar a prática da escrita exige mais do que lançar um olhar sobre, é também aceitar um chamado. Enquanto o primeiro mantém a distância que assegura as posições, o segundo permite ser arrastado por não se sabe o quê. Força que chama e inverte: ser pesquisado por uma escrita. Enquanto chamamento à vida, ela pode exigir silêncio daqueles que precisam aprender a escutar por entre tantos barulhos. Ou então, exigir o grito daqueles que necessitam quebrar o silenciamento. Dar língua para afetos que pedem passagem (ROLNIK, 2007). Na escrita uma vida te chama. Qual?

Guimarães Rosa, na leitura de Maria Bethânia, diz que o sertão é onde o pensamento da gente se forma mais forte que o poder do lugar. Na prisão o poder do lugar está constituído no cotidiano por uma série de técnicas penais que age sobre o indivíduo. Juntamente com elas, uma gama sempre múltipla e variável de detalhes movimentam forças de um existir prisional: produção de vidas criminalizadas, marginalizadas, ferreteadas ${ }^{2}$. Uma vez na prisão, são diversas as grades para a produção da identidade criminal. No meio delas, vozes que gritam uma vida outra. Quem ouve? E para onde vai?

É nesse espaço vigiado, de um tempo gradeado e com tensas relações de convívio que se dá o encontro com a prática da escrita. Na pretensão de seguir os rastros desse fazer e, de algum modo, acompanhar seus movimentos, foram realizados oito encontros de uma oficina educativa. Eles aconteceram às sextas-feiras, das $14 \mathrm{~h}$ às $16 \mathrm{~h}$, com dois reeducandos (Jonas e Cidadão ${ }^{3}$ ). Reuníamonos para conversar e, vez ou outra, ler e escrever. Muito foi dito de ser e estar preso, do silenciamento e isolamento social e dos medos do futuro. Na dissertação de mestrado do presente autor (NASCIMENTO, 2017) podem-se encontrar os detalhes de cada encontro e também como foram organizados em meio às dificuldades de se fazer uma pesquisa no ambiente prisional. O que falam do escrever enquanto atravessam esse momento de estar preso?

\footnotetext{
${ }^{1}$ Biólogo e Mestre em Educação pela UNESP - Rio Claro na linha de pesquisa Linguagem - Experiência Memória - Formação. Atualmente é professor substituto no curso de Pedagogia da Universidade Federal do Tocantins (UFT) - campus Tocantinópolis.

${ }^{2}$ Alusão ao ato de marcar bois com um ferro e, assim, poder identificá-los. Os presos não são marcados fisicamente com este ferro, mas há a marca social registrada nos antecedentes criminais que os qualificam e os identificam na marca de criminosos.

${ }^{3}$ Jonas foi o nome fictício escolhido pelo próprio participante. Cidadão foi o nome fictício escolhido por mim para o outro participante, uma vez que ele mesmo pediu que eu o inventasse. Os nomes fictícios são um modo de não expô-los e preservar sua segurança.
} 
$\mathrm{Na}$ busca por realçar contornos, este texto destaca encontros com vontades de se fazer escutar uma voz que cria tempos divergentes e marginais por entre as malhas do poder disciplinar das prisões (FOUCAULT, 1999; 2002). Aqueles que participaram das oficinas narrativas da pesquisa no Centro de Ressocialização Masculino (CRM) no interior de uma cidade de São Paulo, exigiram divulgação de seus textos em variados espaços, pois querem transformar a imagem do preso, desmontar o discurso que os aprisiona juntamente com as grades da instituição. É na palavra que encontram o instrumento para alargar horizontes e subjetivar outras margens, enfrentar e resistir ao poder prisional. Na escrita, espaço de luta e liberdade.

Jonas diz: a única coisa que eu tenho pra fazer é conscientizar os outros, falar mesmo que as pessoas não me ouçam. Cidadão deixa claro: Esse objeto (a caneta) pra mim, ele é o combustível. Ele me liberta. Tomam para si as palavras e o ato de escrever, vão contra uma ordem do discurso que impõe modos de pensar e dizer; um não ao sufocamento provocado pela construção da identidade prisional. Escrever para ensaiar outros modos de ser que não prisionais, experimentar a si em narratividades. Não se trata aqui de analisar estruturas de uma pessoa presa, menos ainda de encontrar a suposta verdade de um sujeito escritor (DELEUZE, 1988/89). Acontece que ao acompanhar os movimentos da escrita, processos de invenção e vir a ser se apresentam. São os embates dessas forças com o poder institucional que trago neste trabalho.

Palavras singelas, singulares, na espreita para vir à tona; expandir de um silencioso grito. Língua que ecoa e escoa, brota e aflui. Descobertas de uma pesquisa acerca da prática do escrever em privação da liberdade. Trazer narrativas desde essa instituição é o intento de captar qualidades, substâncias e acontecimentos desse meio (DELEUZE, 2011), onde a diversidade de gestos e detalhes compõe práticas cotidianas. Que espécie de gesto seria a escrita? Sabe-se apenas que o escrever pode abrir um espaço-tempo próprio na ordem imposta pelo regime disciplinar e insurgir em margens de possibilidades.

\section{As várias margens de um rio ou do escrever:}

O Centro de Ressocialização (CR) tem seu modo de funcionar: sem excedente populacional, sem vigilância da polícia militar, muros baixos, banheiros separados dos alojamentos, camas de alvenaria, triagem para selecionar a população. Presos do regime provisório, fechado e semi-aberto; convívio mais tranquilo entre funcionários e reeducandos; trabalho para toda a população carcerária e escola para aqueles que não terminaram os estudos. Por meio da humanização da pena é que o CR busca concretizar seu intento de ressocialização efetiva dos indivíduos e abaixar os índices de reincidência criminal (BUENO, 2005).

Por esses e outros aspectos um CR difere das tradicionais penitenciárias, mas ainda assim é uma cadeia e faz funcionar os mecanismos de controle, vigilância e punição. Cidadão apresenta uma relação do CR com o sistema prisional em um dos encontros:

Nesse caso aqui [no CR], a gente é tratado com respeito. Essa é a diferença de um CR. Imagine um rio largo, extenso e com seus braços, seus afluentes, seus riachos. Isso aqui é como se fosse um riacho do grande rio que é o sistema carcerário. Ele é mais lento, mais calmo, mas não deixa de ser um presídio. $O$ CR é um afluente mais calmo, que te dá uma oportunidade melhor. A gente tem aqui um emprego garantido porque tem que trabalhar, tem a oportunidade de estudar. Essa é a parte positiva que eu acho. Só que por outro lado, a gente vive numa regra mais que militar: toque de recolher, toque de levantar, que é a disciplina que se cobra, só que tudo isso com uma grande ameaça. 
Mesmo havendo no CR a garantia de alguns dos direitos básicos do preso, isso não significa que há maior flexibilidade nas regras de convívio. O controle é quase total das atividades, dos indivíduos e das situações cotidianas; a lógica disciplinar e punitiva das prisões tradicionais também está presente ali (COSTA, 2006). É nesse sentido que, ao conversar com um detento do CR, ele explica: Na penitenciária o difícil é a sobrevivência. No CR é a convivência. O desafio de sobreviver no riacho se dá no próprio modo de conviver.

Nos CRs todos os reeducandos possuem trabalho e/ou função. Por um lado a possibilidade de trabalho, remissão de pena e ajuda financeira para a família. Por outro, o regime disciplinar que instaura uma ordem, um tempo e um cotidiano extremamente regrado. Neste espaço, sons e movimentos, mesmo que pequenos, ganham grandes proporções. $\mathrm{O}$ corpo funcional (agentes de segurança internos e externos) é mínimo e a disciplina, rígida. Nesse mecanismo o poder vigilante se espalha por todo o corpo social da instituição: os olhos que veem são todos. A ameaça que corre é uma: voltar ao grande rio e ficar longe da família.

Foi do viver e escrever nessa atmosfera que conversamos nas oficinas. No entremeio dessas questões, lemos seus textos e escrevemos outros. É no ato da escrita que outras faces da vida emergem. Escrever não se trata apenas de tecer um sentido textual e nem somente de fazer do sujeito um escritor. Ali está em ato um ser de passagem que põe em exercício outros modos de vida e é necessário saber vê-los e escutá-los emergindo nesse espaço-tempo prisional, principalmente através das palavras.

Escrever conselhos de como manter-se firme diante dos obstáculos que a vida coloca é o que Jonas canta em suas músicas e escreve em seus poemas. Talvez um conselheiro, mas sem dúvida alguém que sabe fazer vivo seu sonho e, junto dele, manter sua força. É na escrita que se ergue: compor músicas e poder ajudar outras pessoas a enfrentar seus desafios. Jonas diz: $E u$ não desisti, porque na prisão eu continuo a escrever música e Deus me deu música melhor do que eu tinha lá fora. Meu sonho tá vivo. A mesma coisa eu quero: que as pessoas não desistam.

Pode ser também que a escrita ganhe outro modo de se fazer e, como um grito, rompa com a vida silenciada. Cidadão explica: Sempre tive vontade de gritar para que os outros ouvissem o que eu já passei. Embora o tempo seja todo corrido, certo e administrado, é na hora que a gente acha um tempo vago... nesse tempo aí, pra cabeça soltar aquilo que vai acumulando, a hora que sai, sai uma pancada. Grito. Desabafo. Pancada. Escape. Sem projeto, instantânea. A vivência pura mesmo. São esses os caminhos esculpidos pela escrita de Cidadão:

A gente fica num estado emocional e, de repente, você fala: "não, eu preciso desabafar, soltar isso". E ai você pega e solta. Não tem nada de projeto ali. Que nem eu falo, ali tem muitas emoções, muitos sentimentos confusos, difusos. É um estado de espírito que tá ali, uma hora você tá legal, você escreve mais legal; uma hora você tá mais nervoso, uma hora você tá mais apaixonado, uma hora num ar mais de romance... Então é um mix de sentimentos. Não tem um foco direcionado. Na verdade é a vivência pura mesmo ali, pelo menos no meu caso. Eu achei uma válvula de escape. Até mesmo as conversas que a gente tá tendo aqui, esses encontros, pra mim é uma válvula de escape. Se não eu estaria o quê? Andando pelos corredores ou assistindo uma tv, porque já acabou o expediente de trabalho. Então fica aquela expectativa de acabar a semana, sexta à tarde, sábado e domingo...

Juntamente com a produção dos textos, a resistência, mesmo que por alguns instantes. Jonas comenta que foi na prisão que descobriu a poesia: O que eu escrevo aqui é verdade, né? Eu já escrevia, mas escrevia música evangélica. Mas expressar meus sentimentos como poesia foi aqui dentro. Tentar expressar meus sentimentos como poema nunca passou pela minha 
cabeça. Resistem ao projeto prisional de reforma e reeducação do sujeito que os afasta de seus processos de autonomização com a própria vida. Nesse sentido, deixo a pergunta: é no assujeitar que se realiza um trabalho de ressocialização?

Ao conversarmos sobre a ordem imposta na prisão, comento que a submissão é o meio pelo qual se consegue manter o indivíduo na ordem do sistema. Em seguida Cidadão aponta o cerne da questão: Não que saia da ordem, mas que aceitem [os presos] as obrigações calados. Aprender a calar-se, novamente o silenciamento.

O que eu faço? Uma válvula de escape que eu tenho é isso aqui, caderno. Procuro escrever e, de certa forma, eu dou umas agulhadas na sociedade, na humanidade como um todo. É assim que Cidadão não se emudece como quer a prisão e ainda manda carta para políticos: A gente tava numa aula de português, era sobre como fazer uma carta de reclamação quando você está insatisfeito com um produto, uma mercadoria, um serviço prestado. Pô, então vou reclamar pro Temer porque eu não estou gostando do serviço prestado que ele tá fazendo. Se a prisão assujeita, a caneta potencializa: Posso conquistar o mundo se eu quiser. Só utilizar a cabeça e a criatividade e ela faz tudo. Depende de mim - comenta Cidadão ao falar do que pode com a caneta.

A escrita, sozinha, talvez não seja suficiente para transformar toda rede de poderes da prisão, que está longe de ser um lugar que melhora as pessoas. Encontrar as forças de resistência a esse sistema é muito complicado, exige determinação da pessoa para que ela não se transforme naquilo que a prisão quer. Veja o que falam Jonas e Cidadão com relação às mudanças que uma cadeia pode ou não proporcionar:

Para Jonas Cada um de nós tem uma formação desde criança né, que é o ensinamento do pai e isso manda muito. Isso manda muito porque cadeia não muda ninguém. [...] A cadeia nem sempre melhora o preso. Cidadão, por sua vez, diz: Se você cair numa cadeia, você pega sua autoestima, amassa bem amassadinho, joga no lixo. Você ali é nada, pra ninguém mais. Você vai ter que se reconstruir. Parar, buscar força, pensar, você vai ter que se autoconvencer de que você não é aquilo que dizem que você é. A escrita é, no mínimo, essa máquina de outros agenciamentos enunciativos que combate a construção identitária da prisão.

Quando comentam que a cadeia é um lugar onde você tem que buscar essas forças, pergunto para Cidadão quando e como foi que começou a escrever: $O$ que acontece? A prisão me trouxe uma coisa boa. Lá fora, na rua, eu quase não escrevia. Eu tinha o pensamento, mas quase não praticava. E aqui eu tenho tempo pra isso. Escrita como prática do pensamento que fortalece a vida e ajuda a enfrentar o momento que se atravessa. Tempo para criar e respirar, como diz Cidadão:

Porque aqui eu me senti mais confortável de me expressar, pelo respeito. É o que te falo, a sua mente em um CDP ou penitenciária se preocupa mais em sobreviver do que criar. O sistema de um CDP ou de uma penitenciária é a lei da sobrevivência do mais forte. Já aqui você se sente mais tranquilo e isso te dá outra percepção, te faz pensar, aí você não se preocupa mais em se proteger, e sim em criar.

Jonas escrevia músicas antes, mas há uma mudança quando vai preso. Pergunto qual é a diferença e ele responde:

Quando você escreve igual nós escreve, aqui, no momento em que nós tá passando a saudade, a angústia de estar longe de nossos familiares, a ansiedade de ser resolvido logo esse processo, então, quando nós começa a escrever, o sentimento nosso aflui. Ele, a hora que nós escreve muita coisa, 
não sei se com você acontece, mas comigo já aconteceu, de você escrever texto com lágrima nos olhos. Eu começo a escrever e a lágrima desce, aí eu tenho que parar, respirar e continuar. Lá fora já não era assim.

Se as grades impedem os fluxos, a escrita movimenta as águas e faz brotar as palavras. Devir-rio na contramão da barragem construída pelo assujeitamento. Jonas:

É que lá fora eu procurava palavra pra colocar. Hoje as palavras vêm. Ficava horas atrás de palavras que combinassem, que rimassem pra mim montar uma música ou mesmo melodia. Agora, conforme o dia e o momento, o sentimento que eu tô ali na hora, principalmente se é de tristeza, às vezes meio de alegria, que nem sempre a gente tá triste aqui dentro, eu acho as palavras mais fácil, elas vêm mais fácil.

Adentrar campos do íntimo e singularizar-se. Construir e fazer parte de uma comunidade do sensível, onde sentimentos e modos de dizer podem ser partilhados. Aí, colocar-se no lugar do outro. Jonas e Cidadão são escritores de cartas para famílias de outros reeducandos do CR. $\mathrm{Na}$ intimidade com a escrita, eles habitam o comum e sabem dizer daquilo que os atravessa:

Ah, na hora, vou falar a verdade, tem muitas cartas que quando eu escrevo, eu choro. A emoção toma conta de mim, porque eu me ponho mesmo no lugar, como se fosse de verdade meu filho, minha filha ou minha mulher, mesma coisa assim. Porque eles me dão a carta da pessoa, quando chega, pra mim ler. Aí mais ou menos eu tenho uma ideia do que a pessoa tá passando lá, de como tá a vida. Aí, as palavras necessárias pra falar pra eles, eu começo a escrever e vem na mente, Deus vai me dando no coração e eu vou colocando. É legal você poder ajudar as pessoas com a escrita, é bom. (Comentário de Jonas sobre o escrever cartas)

Pergunto, então, se há um estudo para escreverem essas cartas. Primeiramente Cidadão responde: Não, não. Aí que volta lá na sua autorreflexão, no seu encontro de si mesmo. Eu falo por mim, eu me encontrei e, aí, coisa que eu não fazia lá fora, tipo assim, eu não sabia expressar meus sentimentos, meus pensamentos, eu era como eles também, só que eu me busquei, me reinventei. Reinventar-se pela escrita, na e com a escrita. Insisto na pergunta: observam modelos de cartas e compõem um próprio? Jonas responde que não, e diz: Vem instantâneo, na hora. E Cidadão confirma certeiramente: É! É do coração.

\section{Vida prisional entre linhas libertárias:}

A prática de assujeitamento, de seguir a ordem de boca fechada, é uma prática que se preocupa com a reintegração do sujeito à sociedade. Em outras palavras, é um modo de reeducar pela cisão da pessoa com seus processos de autonomização com a vida. Após esta "cirurgia", ele poderá ser reinserido no quadro social, o qual, por sua vez, manteve-se igual. E não deveriam as prisões agir de modo a superar violências? A violência do machismo, do racismo e da marginalização? Em consonância com os pensamentos de Foucault (1999), Wacquant (2011) e Bauman (1999), o modo como funcionam as prisões atuais, atuam mais no sentido de produzir este cenário do que para superá-lo. Se as concepções e práticas de ressocialização não mudarem seu foco, o discurso prisional de reforma continuará a legalizar um processo de formatação, enquadramento e de reinserção social da pessoa aprisionada apenas para perpetuar e obedecer à ordem social já estabelecida (BARATTA, 2004). 
É em meio a este cenário que a prática da escrita na prisão é micropolítica, pois retoma o viver, ressingulariza e autonomiza, reencarna a vida para si: revoluções moleculares, como sugerem Guattari \& Rolnik (1996). Escrever é esse gesto minúsculo que abala o equilíbrio do poder local (DELEUZE \& GUATTARI, 1995) e escapa aos domínios da subjetivação prisional. Movimento não apenas de resistência, mas também de reexistência. Gesto de compor linhas que criam sulcos na carne e bifurcam campos enunciativos para escapar ao dito já tão repetido. Um entranhar-se para encarnar em narrativas outras. Travessias do traço que, pelas letras, insurgem uma vida já não mais aprisionada.

Gesto de compor com palavras que, enquanto se faz, cria também modos de vida. Não só por seu conteúdo registrado nos cadernos, cartas e folhas soltas que carregam consigo, mas também pelo corpo que escreve diante de, e contra, um sistema. A escrita, no meio do viver aprisionado, coloca em ação outros movimentos do corpo, outros tempos do pensamento e da mente (e da própria linguagem) e o modo como usamos aquilo que nos preenche: os afetos. Tudo isso são ações que, de alguma forma, resistem à vida imposta pelas regras e leis prisionais. São eles mesmos ensaiando modos de vida ao invés da pura institucionalização dos corpos e mentes, ferindo seus processos de singularização.

Cidadão e Jonas dizem encontrar forças em um eu oculto que descobrem na prisão. Entendendo esse eu oculto como forças de si ainda estrangeiras a si, encontrá-las faz parte de um processo de desconstrução e reinvenção que se dá com a escrita. Descobri-las e com elas inventar a si um lugar para dizer não daquilo que se é, mas sim daquilo que se está em vias de. Uma força excedente da letra, que transborda na vida e faz desejar. Trabalho pulsional de gerar estranhezas e criar uma vida não captada pelo poder local. Um modo de lidar com aquilo que afeta, de início, como resistência e ultrapassa em reexistência.

Estranhar-se para encontrar forças antes ocultas e entrar em contato com uma fonte criativa. Adentrar outros tempos formativos que rompam com a totalidade identitária inculcada pelas técnicas penais. Foram esses os caminhos que adentrei ao acompanhar a escrita de Jonas e Cidadão. Ela põe em movimento outros agenciamentos enunciativos para a construção de territórios existenciais mais potentes do que os assujeitamentos prisionais. Essa escrita potente que cria e adentra outro tempo-espaço para a invenção de si fora das grades subjetivantes da prisão, sugere uma aproximação com os campos intensivos da formação de si, os quais são processos de se pôr a ser (processo distinto de uma busca pela estruturação do eu ou da identidade), como expõe Guattari (2012, p. 28):

Esses processos de se pôr a ser dizem respeito apenas a certos subconjuntos expressivos que romperam com seus encaixes totalizantes e se puseram a trabalhar por conta própria e a subjugar seus conjuntos referenciais para manifestar a título de indícios existenciais, de linha de fuga processual...

As palavras de Jonas e Cidadão levam a pensar um processo de desconstrução de si, um mergulho na escrita que escapa às formações totalizantes da prisão. Um campo intensivo que agencia outros dizeres de si e de um lugar, descolados dos encaixes que a vida prisional lhes impõe enquanto modos de dizer e pensar. Na prática da escrita encontra-se com esse ser de passagem que não admite a marca criminal e produz o agenciamento do não criminoso como outros territórios existenciais. São linhas de força que arrastam para fora das identidades, sempre. De fora para poder desconstruir dizeres como: "bandido bom é bandido morto".

Partir com a cartografia enquanto modo de fazer pesquisa na prisão seja talvez atentar e captar esses outros processos formativos que escapam à formação institucional e fazem aparecer 
outros tempos do viver. Vida menor, partículas moleculares em vibração a produzirem existências singulares, ou, como propõe Guattari (2012), vetores potenciais de subjetivação:

\begin{abstract}
Em geral trata-se de algo que se coloca atravessando à ordem normal das coisas - uma repetição contrariante, um dado intensivo que apela outras intensidades a fim de compor outras configurações existenciais. Tais vetores dissidentes se encontram relativamente destituídos de suas funções de denotação e de significação, para operar enquanto materiais existenciais descorporificados. [...] uma desterritorialização suave pode fazer evoluir os Agenciamentos de um modo processual construtivo. É aí que se encontra o coração de todas as práxis ecológicas: as rupturas assignificantes, os catalisadores existenciais estão ao alcance das mãos, mas, na ausência de um Agenciamento de enunciação que lhes dê um suporte expressivo, eles permanecem passivos e correm o risco de perder sua consistência (é mais por esse lado que convirá procurar raízes da angústia, da culpabilidade e, de maneira geral, de todas as reiterações psicopatológicas). (GUATTARI, 2012, p. 28)
\end{abstract}

Vetores potenciais de subjetivação que escapam ao poder prisional, sem dúvidas, circulam pelas linhas escritas e corpos escritores de Jonas e Cidadão. A singularidade não se conforma, por isso grita onde pode. Mas quando o CR, mesmo ao propor um novo modelo de gestão prisional, usa dos mesmos métodos e regras disciplinadoras das prisões tradicionais e faz prevalecer sobre o indivíduo os interesses do Estado em controlá-lo (COSTA, 2006), opera de modo a impossibilitar agenciamentos de enunciação que deem os suportes expressivos para sustentar os vetores potenciais de subjetivação. Todo vetor singularizante que escapa às regras, à discursividade prisional, é logo desconectado de agenciamentos outros que poderiam atuar no sentido de dinamizar processos de autonomização e produção de outros modos de vida desde dentro da prisão.

Desconectar vetores: é aí onde age o rígido cotidiano prisional. Na atmosfera do controle, vigilância e punição, ele atua para que não se possa dizer de outras coisas que não dos crimes, do processo, da punição, da culpa. As prisões assim agem para que não se possa ser outra coisa que um preso. Com as desconexões através das ameaças, silenciamentos e assujeitamentos, é por onde se recai em questões morais, da individualização da violência, da culpabilidade e de perpetuação do racismo. Que espaço há, mesmo com garantia de direitos, na instituição prisão para o agenciamento dos vetores de singularização e quebra com a lógica de produção criminal?

A prisão não é para qualquer pessoa, ela tem um público específico a ser capturado: os pobres, jovens e negros (DEPEN, 2017; WACQUANT, 2011). É com essa população que o maquinário prisional continua a produzir o perfil do criminoso a ser perseguido nas ruas. Contornam a pobreza e a cor negra como os supostos atores da violência social e merecedores da punição penal no país. E onde é que se escuta o preso? Apenas no tribunal? Quando e onde os presos podem discutir as condições da prisão? Que visibilidade eles têm? Quais são os espaços onde se fala da vida aprisionada e de suas mazelas?

Não basta garantir direitos aos encarcerados e usar disso como uma regalia a ser cortada em casos de indisciplina. Os direitos devem ser garantidos com vistas à superação das condições de marginalização, assim como trabalhar em prol dos processos de autonomização da vida e, por isso, por relações sociais mais potentes do que assujeitadas. Ainda assim, não basta o contento por haver melhores prisões. É preciso pensar em como podemos ter cada vez mais menos prisões, afinal, por que mantê-las se funcionam hegemonicamente para promover o racismo, a violência e o medo? (DAVIS, 2017).

Por fim, a escrita não resolve a prisão, mas faz algo nela acontecer. Promove rachaduras, fala e chama por outros tempos e possibilidades para se viver a vida. Assim ela se apresenta e convida 
a reexistir. Da vida aprisionada, seja na prisão ou em quaisquer outras relações que se constroem fora dela, a escrita é capaz de fazer insurgir as forças de um ser vivente para seu voo livre.

\section{Referências}

BARATTA, A. Resocialización o controle social. Por un concepto crítico de "reintegración social" del condenado. In: ELBERT, C. A. (Dir.); BELLOQUI, L. (Coord.). Criminologia y sistema penal: compilación in memoriam. Montevideo-Buenos Aires: Editora B de F. p. 376393, 2004b.

BAUMAN, Z. Globalização: as consequências humanas. 1. ed, Rio de Janeiro: Jorge Zahar, 1999.

BUENO, L. Humanizando a Política Carcerária: Cidadania no Cárcere. Disponível em: <http://bibliotecadigital.fgv.br/dspace/bitstream/handle/10438/15747/relatorio_completo_200 5.pdf?sequence=1>. Acesso em: 07/06/2017.

COSTA, G. M. As Organizações Não Governamentais no Sistema Penitenciário do Estado de São Paulo: protagonistas constitutivas de novos modelos prisionais ou reprodutoras dos modelos tradicionais? Dissertação (Mestrado em Serviço Social) - Pontifícia Universidade Católica de São Paulo, São Paulo, 112f, 2006.

DAVIS, A. As prisões são obsoletas? Disponível em: <https://medium.com/revistasubjetiva/cap\%C3\%ADtulo-1-de-pris\%C3\%B5es-s\%C3\%A3o-obsoletas-de-angela-davisec1a3e3c6bb4>. Acesso em: 08/08/2018, publicado em 28/02/2017.

DELEUZE, G. Crítica e Clínica. 2. ed. São Paulo: Editora 34: 2011. . O abecedário de Gilles Deleuze; 1988/89.

DELEUZE, G; GUATTARI, F. Mil Platôs - capitalismo e esquizofrenia. v. 1. Rio de Janeiro: Ed. 34, 1995.

DEPEN. Levantamento nacional de informações penitenciárias: INFOPEN. SANTOS, T. (Org.); ROSA, M. I. (Colab.). Brasília: Ministério da Justiça e Segurança Pública. Departamento Penitenciário Nacional, 2017.

FOUCAULT, M. Em defesa da sociedade: curso no Collège de France (1975-1976). São Paulo: Martins Fontes, 1999.

. Vigiar e punir: nascimento da prisão. 25ª Ed., Petrópolis: Vozes, 2002.

GUATTARI, F. As três ecologias. 21. ed. Campinas, SP: Papirus, 2012.

GUATTARI, F.; ROLNIK, S. Micropolítica: cartografias do desejo. 4. ed. Petrópolis: Vozes, 1996.

NASCIMENTO, R. C. Silenciosos gritos por entre as grades e as ruas: escrita e invenções de si no Centro de Ressocialização Masculino de Rio Claro. Dissertação (Mestrado em Educação) 
- Programa de Pós-Graduação em Educação da Universidade Estadual Paulista - Unesp, Rio Claro, 169f, 2017.

OLIVEIRA, T. R. M.; PARAÍSO, M. A. Mapas, danças, desenhos: a cartografia como método de pesquisa em educação. Pro-posições, v. 23, n. 3 (69), p. 159-178, 2012.

ROLNIK, S. Cartografia sentimental: transformações contemporâneas do desejo. 2. ed. Porto Alegre: Sulina/Ed. UFRGS, 2007.

WACQUANT, L. As prisões da miséria. 2. Ed. Rio de Janeiro: Zahar, 2011. 